\title{
Overexpression of ARF1 is associated with cell proliferation and migration through PI3K signal pathway in ovarian cancer
}

\author{
GUIFANG GU $^{1 *}$, YANNAN CHEN $^{2 *}$, CHENGWEI DUAN $^{3}$, LINSEN ZHOU $^{4}$, CAIWEN CHEN $^{5}$, \\ JIE CHEN $^{6}$, JIALIN CHENG ${ }^{2}$, NANNAN SHI ${ }^{2}$, YUNFENG JIN ${ }^{2}$, QINGHUA XI ${ }^{2}$ and JIANXIN ZHONG ${ }^{2}$ \\ ${ }^{1}$ Department of Obstetrics and Gynecology, Nantong Third People's Hospital; ${ }^{2}$ Department of Obstetrics \\ and Gynecology, Affiliated Hospital of Nantong University, Nantong University, Nantong, Jiangsu 226001; \\ ${ }^{3}$ Department of Science and Education, The Second People's Hospital of Nantong, Nantong, Jiangsu 226002; \\ ${ }^{4}$ Department of Obstetrics and Gynecology, Affiliated Maternal and Child Care Service Centre, Nantong University, \\ Nantong, Jiangsu 226001; ${ }^{5}$ Department of Obstetrics and Gynecology, Yixing People's Hospital, Wuxi, \\ Jiangsu 214200; ${ }^{6}$ Department of Oncology, Jiangyin People's Hospital, Jiangyin, Jiangsu 214401, P.R. China
}

Received July 27, 2016; Accepted December 15, 2016

DOI: 10.3892/or.2017.5388

\begin{abstract}
ADP-ribosylation factor 1 (ARF1) is a small G protein that regulates many cellular processes such as reorganization of the actin cytoskeleton and is highly expressed in various tumor cells and tissues. However, the role of ARF1 in ovarian cancer progression remains unknown. In the present study, we explored the expression patterns of ARF1 in clinical ovarian cancer samples and adjacent noncancerous tissues. The results revealed that ARF1 overexpressed in EOC tissues and cell lines, compared with the adjacent non-tumorous tissues and normal ovarian cells. In addition, the immunoreactivity of ARF1 was positively correlated with EOC grade and Ki-67 expression. Knockdown of ARF1 expression notably inhibited cell proliferation and migration rate of EOC cells by the auxiliary of PI3K. Taken together, our findings provide new insights into the functional role of ARF1 on EOC cell growth and migration and it may serve as a diagnostic and therapeutic target.
\end{abstract}

\section{Introduction}

Ovarian cancer, which is the fifth leading cause of tumorassociated mortalities in female $(1,2)$, accounts for $4 \%$ of

Correspondence to: Dr Jianxin Zhong or Dr Qinghua Xi, Department of Obstetrics and Gynecology, Affiliated Hospital of Nantong University, Nantong University, 20 Xi'si Road, Nantong, Jiangsu 226001, P.R. China

E-mail: ntdxzjx@163.com

E-mail: ntdxfsyyxqh@126.com

*Contributed equally

Abbreviations: ARF1, ADP ribosylation factors; EOC, epithelial ovarian cancer

Key words: ADP ribosylation factors, ovarian cancer, proliferation, migration, therapeutic target all cancers in women and is still the leading cause of death in gynecologic malignancies (3). Besides, among all ovarian cancers, epithelial ovarian cancer (EOC) accounts for $80-90 \%$ (4), and has the highest mortality rate of all gynecological malignancies. Regardless of advances in treatment techniques, long-term survival rates for patients remain poor (2), maybe because of the lack of early symptoms, late diagnosis and invalid chemotherapy (5). Therefore, to ameliorate poor survival outcomes, obtaining earlier diagnosis and new prognostic indicators is critical.

Progression of cancer from normal tissue to carcinomas requires many steps (6), involving the disharmony of cell division, the inappropriate activity of a series of different genes and proteins. Cell invasion, which is a ubiquitous process, is tightly regulated by multiple signaling proteins, such as plasma membrane receptors, scaffold and small GTP-binding proteins (7). Through disrupting the program regulating cell cycle entry and death, activation or upregulation of oncogenes disrupts these orderly processes (8). Whereby, one of the best characterized oncogenes is the small GTP-binding protein. It has been reported that ADP ribosylation factors (ARF), another family of small GTP-binding proteins, are closely related to cancer progression (9). Like all other GTPases, ARFs cycle between their inactive (GDP bound) and active (GTP bound) form. In most cases, they act as molecular switches to turn on a couple of signaling cascades associated with vesicle formation, remodeling of the actin cytoskeleton and transformation of membrane lipids (10).

ARF1, ADP-ribosylation factor 1, is mainly found in the Golgi apparatus and acts to promote carrier vesicle biogenesis by nucleating the assembly of coat protein complexes at sites of vesicle formation (11). Several studies have suggested that ARF1 can also localize to the plasma membrane transmitting signals from transmembrane proteins $(12,13)$. In addition to their conventional roles of vesicle formation, ARF1 plays important roles in a wide range of physiological and pathophysiological processes in tumor formation, including inter- and intracellular signaling, transcription, DNA repair 
pathways, cell cycle regulation, and mitosis, as well as necrosis and apoptosis (14). A role for ARF1 in the control of integrin-mediated cell adhesion was indicated by studies on Brefeldin A (BFA)-resistant Arf GEFs and it was shown that ARF1 mediated paxillin recruitment to the focal adhesions and potentiated Rho-stimulated stress fiber formation in fibroblasts (15). Furthermore, inhibition of ARF1 activation by targeting ARNO impaired ARNO-dependent migration of MDCK cells (16). In invasive breast cancer cells, stimulation of the epidermal growth factor receptor led to the activation of ARF1, the PI3K pathway, and ultimately cell migration and proliferation (17). Another study also demonstrated that, phosphorylation of the membrane-associated non-receptor tyrosine kinase Src was regulated by ARF1 (18). While Src has been shown to induce the migration, proliferation, adhesion, and growth of cancer cells and has been reported to be overexpressed or activated in many cancers including breast cancer $(19,20)$.

In the current study, we found that ARF1 was significantly overexpressed in EOC specimens and cell lines, compared with adjacent non-tumorous ones. The expression of ARF1 is bound up with clinicopathological variables and prognostic implications. In addition, we detected the effect of ARF1 knockdown on proliferation and migration of EOC. The results demonstrated that the small GTPase is critical for both cell proliferation and migration by directly regulating the activation of the PI3K pathway, and the PI3K pathway may also be upstream of ARF1. By defining the signaling pathways regulating proliferation and migration of EOC cells, we will be able to identify new therapeutic targets for the treatment of these aggressive types of cancers.

\section{Materials and methods}

Patients and tissue samples. The fresh samples were put into liquid nitrogen immediately after surgical removal and maintained at $-80^{\circ} \mathrm{C}$ until use for western blot analysis. We investigated 119 cases of EOC (including 63 serous papillary adenocarcinoma, 19 mucinous papillary carcinoma, 18 endometrioid adenocarcinoma and 19 clear cell carcinoma) provided by the Obstetrics and Gynecology Department of the Affiliated Hospital of Nantong University for immunohistochemical analysis. All of these patients underwent surgical resection without preoperative chemotherapy in the surgery department. All patients were followed up for 1-60 months. The main clinical and pathologic features of the patients, including age, tumor grade, the International Federation of Gynecology and Obstetrics (FIGO) stages, lymph node metastasis, tumor invasion and survival are shown in Table I.

Antibodies. The antibodies used for western blot analysis immunohistochemistry and immunofluorescence were as follows: i) ARF1 antibody (anti-mouse, Santa Cruz Biotechnology, Inc., Santa Cruz, CA, USA), ii) Ki-67 antibody (anti-mouse, Santa Cruz Biotechnology, Inc.), iii) PCNA antibody (anti-mouse, Santa Cruz Biotechnology, Inc.), iv) cyclin D1 antibody (anti-rabbit, Santa Cruz Biotechnology, Inc.), and v) Akt1 antibody (anti-mouse, Santa Cruz Biotechnology, Inc.), vi) p-Akt1/2/3(Ser473) antibody (antirabbit, Santa Cruz Biotechnology, Inc.), vii) p-Akt1 (Thr308) antibody (anti-rabbit, Santa Cruz Biotechnology, Inc.), viii) GAPDH antibody (anti-rabbit, Santa Cruz Biotechnology, Inc.).

Western blot analysis. Frozen EOC tissues and protein were used for western blot analysis. They were promptly homogenized in a homogenization buffer [ $1 \mathrm{M}$ Tris $\mathrm{HCl}, \mathrm{pH} 7.5,1 \%$ Triton X-100, 1\% Nonidet p-40 (NP-40), 10\% sodium dodecyl sulfate (SDS), $0.5 \%$ sodium deoxycholate, 0.5 M EDTA, leupeptin $10 \mu \mathrm{g} / \mathrm{ml}$, aprotinin $10 \mu \mathrm{g} / \mathrm{ml}$, and $1 \mathrm{mM}$ PMSF]. The lysates were cleared by centrifugation at $12,000 \mathrm{rpm}$ for $20 \mathrm{~min}$ at $4^{\circ} \mathrm{C}$. Protein concentrations were determined with a Bio-Rad protein assay (Bio-Rad Laboratories, Inc., Hercules, CA, USA). The total cellular protein extracts were separated by sodium dodecyl sulfate-polyacrylamide gel electrophoresis (SDS-PAGE) and transferred to polyvinylidenedifluoride filter (PVDF) membranes (Millipore, Bedford, MA, USA). After the membranes were blocked in 5\% nonfat milk in PBST for $2 \mathrm{~h}$, they were incubated with appropriate primary and secondary antibodies. The membrane was detected using an enhanced chemiluminescence system (ECL; Pierce Biotechnology, Inc., Rockford, IL, USA). The experiments were carried out three separate times.

Immunohistochemistry (IHC) staining. IHC stain was conducted as previously described (21). The sections were dewaxed in xylene for $15 \mathrm{~min}$ and rehydrated in graded ethanols. Then, endogenous peroxidase activity was blocked by soaking in $3 \%$ hydrogen peroxide for $30 \mathrm{~min}$. Thereafter, immunoreactivity was enhanced by pressure cooking by incubating the tissue sections for $3 \mathrm{~min}$ in $0.1 \mathrm{M}$ citrate buffer. After rinsing in phosphate-buffered saline (PBS, $\mathrm{pH}$ 7.2), 10\% goat serum was applied to block any nonspecific reactions for $1.5 \mathrm{~h}$. Then, the sections were incubated with ARF1 antibody (diluted 1:100) and Ki-67 antibody (diluted 1:800) for $3 \mathrm{~h}$ at room temperature (RT). The sections were washed three times with phosphate-buffered saline (PBS). After rinsing in water, the sections were counterstained with hematoxylin, dehydrated, and cover slipped.

Immunohistochemistry analysis. Five high-power views in each specimen were selected randomly for assessment; and at least 500 cells were counted to determine the labeling index (LI), representing the percentage of immunostained cells that is related to the total number of cells. To evaluate the immunoreaction of ARF1, intensity was estimated in comparison with the control and scored as follows: 0 , negative staining; 1 , weak staining; 2, moderate staining; and 3, strong staining. Scores which represent the percentage of tumor cells stained positive were as follows: $0,<1 \%$ positive tumor cells; $1,1-10 \%$; $2,10-50 \% ; 3,50-75 \%$; and $4,>75 \%$. Then, we multiplied the two scores, and a score of 0 was considered negative, 2-3 was weak, 4-5 was moderate, and 6-7 was considered strong. For statistical analysis, 0-3 was counted as low expression, and 4-7 were overexpression (15). As for statistical analysis of Ki-67, a cutoff value was used to distinguish tumors with a low $(<50.7 \%)$ or high $(\geq 50.7 \%)$ level of Ki-67 expression.

Immunofluorescence. Cells were plated on glass coverslips and grown for $48 \mathrm{~h}$ prior to staining, allowing transfection when 
Table I. Expression of ARF1 and related clinicopathological parameters in the 119 human ovarian cancer specimens.

\begin{tabular}{|c|c|c|c|c|c|}
\hline \multirow[b]{2}{*}{ Characteristics } & \multirow[b]{2}{*}{ Total } & \multicolumn{2}{|c|}{$\begin{array}{c}\text { ARF1 } \\
\text { expression }\end{array}$} & \multirow[b]{2}{*}{ P-value ${ }^{a}$} & \multirow[b]{2}{*}{$\chi^{2}$-value } \\
\hline & & Low & High & & \\
\hline \multicolumn{6}{|c|}{ Age (24-80 years, mean 55 years) } \\
\hline$\leq 50$ & 40 & 17 & 23 & 0.563 & 0.335 \\
\hline$>50$ & 79 & 38 & 41 & & \\
\hline \multicolumn{6}{|c|}{ Histologic subtype } \\
\hline Serous & 63 & 26 & 37 & 0.384 & 3.047 \\
\hline Mucinous & 19 & 12 & 7 & & \\
\hline Endometrioid & 18 & 9 & 9 & & \\
\hline Clear cell & 19 & 8 & 11 & & \\
\hline \multicolumn{6}{|c|}{ Histological grade } \\
\hline Low & 49 & 30 & 19 & $0.006^{\mathrm{b}}$ & 7.546 \\
\hline High & 70 & 25 & 45 & & \\
\hline \multicolumn{6}{|l|}{ FIGO stage } \\
\hline $\mathrm{I} / \mathrm{II}$ & 60 & 35 & 25 & $0.008^{\mathrm{b}}$ & 7.146 \\
\hline III/IV & 59 & 20 & 39 & & \\
\hline \multicolumn{6}{|c|}{ Lymph node metastasis } \\
\hline Negative & 86 & 46 & 40 & $0.010^{\mathrm{b}}$ & 6.594 \\
\hline Positive & 33 & 9 & 24 & & \\
\hline \multicolumn{6}{|c|}{ Ki-67 expression } \\
\hline Low & 55 & 33 & 22 & $0.005^{\mathrm{b}}$ & 7.814 \\
\hline High & 64 & 22 & 42 & & \\
\hline
\end{tabular}

${ }^{\text {a }}$ Statistical analyses were performed by the Pearson's $\chi^{2}$ test. ${ }^{\mathrm{b}} \mathrm{P}<0.05$ was considered significant.

needed. Cells were then rinsed twice in PBS before fixation in $2 \%$ paraformaldehyde for $25 \mathrm{~min}$. They were permeabilized with $0.1 \%$ Triton X-100 in PBS for 25 min. After washing in PBS supplemented with $0.05 \%$ Tween-20 (PBST), cells were incubated for $1 \mathrm{~h}$ at room temperature with the appropriate antibodies in PBST supplemented with 10\% FCS. Coverslips were then rinsed twice with PBST, and incubated for $1 \mathrm{~h}$ at room temperature with the secondary antibodies.

After that, the coverslips were mounted with an antibleaching glycerol mixture. Samples were viewed using a Zeiss Axiophot epifluorescence microscope with a 1003 immersion oil objective. The images, given by the Hamamatsu C4880 cooled CCD camera connected to the Serie 150/151 from Imaging Technology Inc., were acquired by Khoros software package from Khoral Research Inc. In order to correct an uneven illumination from the mercury lamp, a shading correction was applied to the images.

Cell culture and cell cycle analysis. Human ovarian carcinoma cell lines HO-8910 were purchased from the Shanghai Institute of Cell Biology, and cultured in RPMI-1640 supplemented with $10 \%$ heat-inactivated fetal calf serum and $100 \mathrm{U} / \mathrm{ml}$ penicillin-streptomycin mixture (Gibco-BRL,
Table II. Survival status and clinicopathological characteristics in the 119 human ovarian cancer specimens.

\begin{tabular}{|c|c|c|c|c|}
\hline \multirow[b]{2}{*}{ Characteristics } & \multirow[b]{2}{*}{ Total } & \multicolumn{2}{|c|}{ Survival status } & \multirow[b]{2}{*}{ P-value } \\
\hline & & Died & Alive & \\
\hline \multicolumn{5}{|c|}{ Age (24-80 years, mean 55 years) } \\
\hline$\leq 50$ & 40 & 23 & 17 & \multirow[t]{2}{*}{0.939} \\
\hline$>50$ & 79 & 46 & 33 & \\
\hline \multicolumn{5}{|l|}{ FIGO stage } \\
\hline $\mathrm{I} / \mathrm{II}$ & 60 & 28 & 32 & \multirow[t]{2}{*}{$0.012^{\mathrm{b}}$} \\
\hline III/IV & 59 & 41 & 18 & \\
\hline \multicolumn{5}{|c|}{ Histological grade } \\
\hline Low & 18 & 21 & 28 & \multirow[t]{2}{*}{$0.005^{\mathrm{b}}$} \\
\hline High & 30 & 48 & 22 & \\
\hline \multicolumn{5}{|c|}{ Histologic subtype } \\
\hline Serous & 63 & 41 & 22 & \multirow[t]{4}{*}{0.291} \\
\hline Mucinous & 19 & 8 & 11 & \\
\hline Endometrioid & 18 & 9 & 9 & \\
\hline Clear cell & 19 & 11 & 8 & \\
\hline \multicolumn{5}{|c|}{ Lymph node metastasis } \\
\hline Negative & 86 & 48 & 38 & \multirow[t]{2}{*}{0.439} \\
\hline Positive & 33 & 21 & 12 & \\
\hline \multicolumn{5}{|l|}{ Ki-67 expression } \\
\hline Low & 55 & 25 & 30 & \multirow[t]{2}{*}{$0.010^{\mathrm{b}}$} \\
\hline High & 64 & 44 & 20 & \\
\hline \multicolumn{5}{|c|}{ ARF1 expression } \\
\hline Low & 55 & 19 & 36 & \multirow[t]{2}{*}{$<0.001^{\mathrm{b}}$} \\
\hline High & 64 & 50 & 14 & \\
\hline
\end{tabular}

${ }^{\text {a }}$ Statistical analyses were performed by the Pearson's $\chi^{2}$ test. ${ }^{\mathrm{b}} \mathrm{P}<0.05$ was considered significant.

Grand Island, NY, USA) at $37^{\circ} \mathrm{C}$ and $5 \% \mathrm{CO}_{2}$. For the analysis, cells were harvested at the proper time and fixed in $70 \%$ ethanol overnight at $4^{\circ} \mathrm{C}$ and then incubated with $1 \mathrm{mg} / \mathrm{ml} \mathrm{RNase}$ for $30 \mathrm{~min}$ at $37^{\circ} \mathrm{C}$. Subsequently, the cells were stained with propidium iodide (PI, $50 \mathrm{mg} / \mathrm{ml}$; BectonDickinson, San Jose, CA, USA) in PBS, 0.5\% Tween-20, then we analyzed the cells using a Becton-Dickinson BD FACScan flow cytometer and CellQuest acquisition and analysis software.

Plasmid constructs shRNA and transfection. Short hairpin RNAs (shRNA) were designed and provided by GeneChem (Shanghai, China). The target sequences were as follows: 5'-GAACCAGAAGUGAACGCGA-3', designated sh-1; 5'-CGGCCGAGATCACAGACAAG-3', designated sh-2; and 5'-GCCATTAGAAAGCGCAACCAG-3', designated sh-3. HO-8910 cells were plated the day before transfection at $50-70 \%$ confluency. The cells were then transfected with siRNAs at final concentrations of $50 \mathrm{nM}$ with Lipofectamine 2000. The cells were collected after $48 \mathrm{~h}$ for the following assays. 


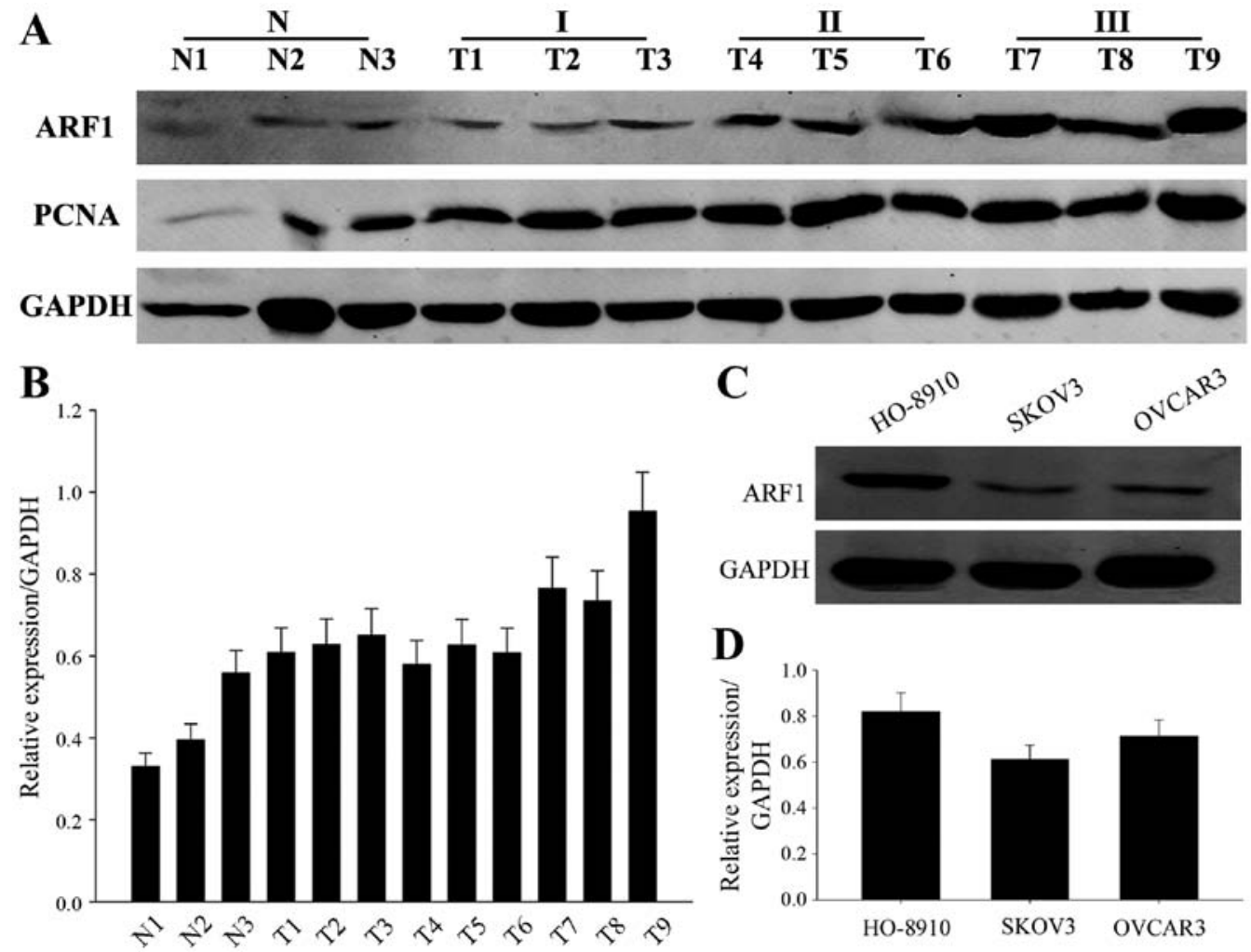

Figure 1. The expression of ARF1 in EOC tissues and EOC cell lines. (A) Western blot analysis of expression of ARF1 in different grades of EOC tissues, including three normal ovarian tissues and three grades of ovarian cancer tissues (each grade contains three different specimens). (B) The bar chart demonstrating the expression of ARF1 in EOC tissues to GAPDH by densitometry. The data are mean \pm SD. (C) Western blot performed to detect the expression of ARF1 in three human EOC cell lines: HO-8910, SKOV3 and OVCAR3. (D) The bar chart demonstrating the expression of ARF1 in EOC cell lines to GAPDH by densitometry. The data are mean \pm SD. GAPDH was used as a loading control and each experiment repeated at least three times.

Flow cytometric analysis. Cells were prepared into a singlecell suspension, and then fixed with $70 \%$ ethanol at $-20^{\circ} \mathrm{C}$ for $24 \mathrm{~h}$. Next, cells were incubated with $1 \mathrm{mg} / \mathrm{ml}$ RNase in PBS at $37^{\circ} \mathrm{C}$ for $30 \mathrm{~min}$ and stained with $0.5 \mathrm{mg} / \mathrm{ml}$ propidium iodide. The DNA contents were analyzed by a FACScan flow cytometer (Becton-Dickinson, Lincoln Park, NJ, USA). Three independent experiments were conducted to ensure the results.

Co-immunoprecipitation assay. Co-immunoprecipitation assay was conducted as previously described (22). HO-8910 cells were harvested and lysed in buffer $(50 \mathrm{mmol} / \mathrm{l} \mathrm{Tris}-\mathrm{HCl}$, pH 7.5, $150 \mathrm{mmol} / \mathrm{l} \mathrm{NaCl}, 5 \mathrm{mmol} / \mathrm{l}$ EDTA, $1 \% \mathrm{NP}-40,0.5 \%$ deoxycholate, $0.1 \%$ SDS). Supernatants $(30 \mu \mathrm{l})$ were collected as input. The remaining liquids were pre-cleared with $30 \mu \mathrm{l}$ protein A/G agarose (Santa Cruz Biotechnology, Inc.) on a rocker at $4^{\circ} \mathrm{C}$ for $2 \mathrm{~h}$. After that, the pre-cleared supernatants were separated into two and incubated with the $6 \mu \mathrm{l}$ ARF1 antibody and $0.3 \mu \mathrm{l}$ mouse $\mathrm{IgG}$, respectively, at $4^{\circ} \mathrm{C}$ overnight with gentle agitation. Then, the samples were incubated with $30 \mu 1$ protein $\mathrm{A} / \mathrm{G}$ at $4^{\circ} \mathrm{C}$ for $2 \mathrm{~h}$ with gentle agitation, then deposits were collected. The immune complexes were then analyzed by immunoblotting using antibodies against ARF1 and PI3K.

Cell viability assay. Cell viablity assay was measured using the Cell Counting Kit-8 (CCK-8) according to the manufacturer's instructions (Dojindo, Kumamoto, Japan) to judge the ability of cell proliferation. Cells transfected with siRNA were seeded into a 96-well plate and cultured in RPMI-1640 medium or control PBS with $100 \mu 1$ in each well at a concentration of $2 \times 10^{4}$ cells/well in a volume of $100 \mu \mathrm{l}$ culture medium and grown overnight. CCK-8 reagents (Dojindo) were then added to each well followed by incubation for an additional $2 \mathrm{~h}$ at $37^{\circ} \mathrm{C}$. The absorbency was measured at a test wavelength of $490 \mathrm{~nm}$ and a reference wavelength of $630 \mathrm{~nm}$ using a microplate reader (Bio-Rad Laboratories, Inc.). The experiments were repeated at least 3 times.

Wound healing assays. Wound healing was conducted as previously described (23). Growing in a monolayer in 6-well plates, the cell growth was in nearly complete confluence. The cells were serum starved for $12 \mathrm{~h}$ after $36 \mathrm{~h}$ of transfection with control-shRNA, ARF1-shRNA\#2. Afterwards, the monolayer was scratched with a $10 \mathrm{ml}$ pipette tip, the cells were washed with PBS and cultured in the 1640 medium with 5\% fetal bovine serum (FBS), and an inverted Leica phase contrast microscope (Leica DFC300 FX) was used to photograph the cells under x20 objective lens at 0,24 , and $36 \mathrm{~h}$.

Statistical analysis. Statistical analysis was performed using SPSS 10.0 software (SPSS Inc., Chicago, IL, USA). The association between ARF1 and Ki-67 expression and clinicopathological features was analyzed using the Pearson's $\chi^{2}$ test. ARF1 and Ki-67 expression was studied using the Spearman rank correlation test, because the data were not normally distributed. For analyzing the survival data, Kaplan-Meier 
A

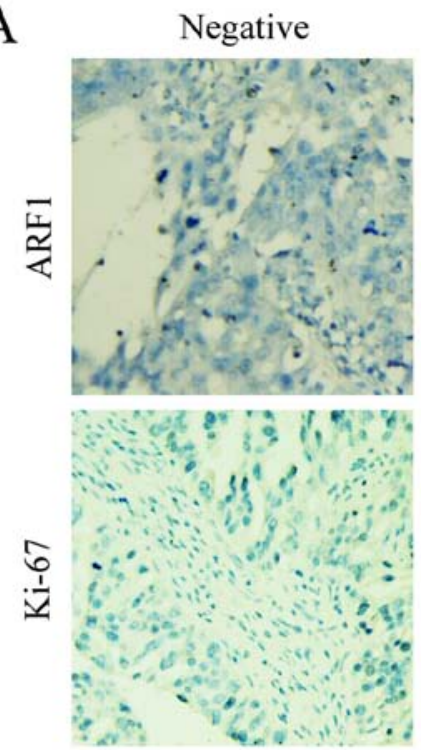

Low-grade

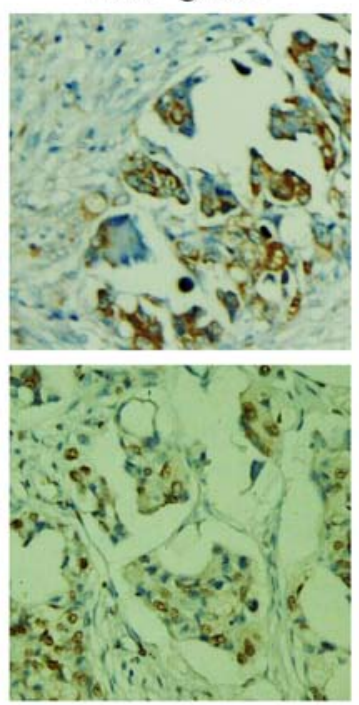

High-grade

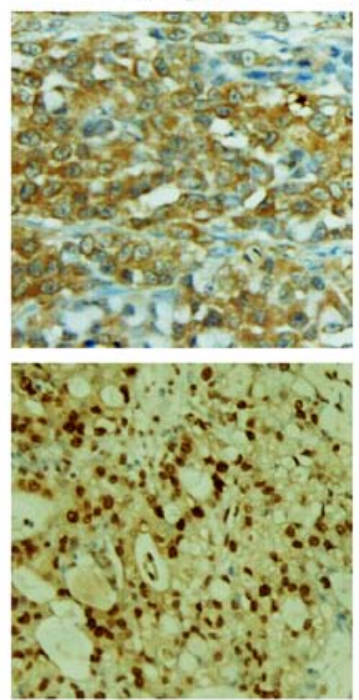

B

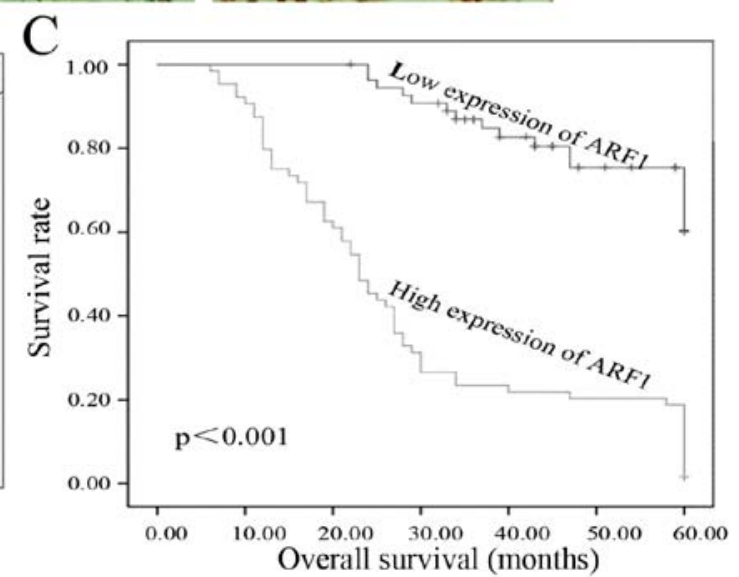

Figure 2. (A) Immunohistochemical stain of ARF1 and Ki-67 in different grades of EOC tissues. (B) Relationship between ARF1 and Ki-67 proliferation index expression in EOC. Scatterplot of ARF1 against Ki-67 with the regression lines showed a correlation using Spearman's correlation coefficient. (C) KaplanMeier survival curves for low ARF1 expression versus high ARF1 expression in 119 EOC patients. Data showed that patients with a lower expression of ARF1 had a longer survival than the others.

curves were constructed, and the log-rank test was performed. Multivariate analysis was performed using Cox's proportional hazards model, with $\mathrm{P}<0.05$ considered statistically significant. The results are expressed as the mean \pm SD.

\section{Results}

Expression and distribution of ARF1 in EOC issues and cell lines and its correlation with survival. To verify the tumor entities with frequent aberrant ARF1 expression in EOC, we first examined ARF1 protein expression by western blot using several surgical specimens and three kinds of EOC cell lines (Fig. 1). These surgical specimens included three normal ovarian tissues and different grades of ovarian cancer tissues, and the three EOC cell lines were HO-8910, SKOV3 and OVCAR3. As shown in Fig. 1A and B, the expression of ARF1 was obviously higher in tumors when compared to the normal ovarian tissues, and its expression was positive correlated with the tissue grade. Simultaneously, ARF1 was also highly expressed in these three EOC cell lines (Fig. 1C and D), especially in the HO-8910 cell lines. Thus, we initially thought that ARF1 may be associated with EOC progression.
In order to confirm the above, immunohistochemistry analysis of ARF1 and Ki-67 (a cell proliferation index) was performed using 119 samples from patient with EOC. As shown in Fig. 2A, we found that there was no or little ARF1 or Ki-67 expression among these low-grade EOC tissues. On the contrary, as the pathological grade increased, the expression of ARF1 and Ki-67 was upregulated (Fig. 2A). Moreover, we also found that, ARF1 was expressed mainly in cytomembrane, while the location of Ki-67 was mainly in the nucleus. Thus, the expression of ARF1 was higher in EOC tissues and EOC cell lines and it was positively correlated with grade.

Correlation of ARF1 expression with clinicopathological features of EOC. To further clarify the clinicopathological significance of ARF1 expression in EOC, we evaluated the association of ARF1 expression with clinicopathologic variables of patients with EOC by Pearson's $\chi^{2}$ test. The clinicopathological data of patients are summarized in Table I. From the results of statistical analysis, we could find that the expression of ARF1 was significantly associated with the histological grade $(\mathrm{P}=0.006)$, FIGO stage $(\mathrm{P}=0.008)$, lymph node metastasis $(\mathrm{P}=0.010)$, and Ki-67 expression $(\mathrm{P}=0.005)$ (Table I). Besides, 
A

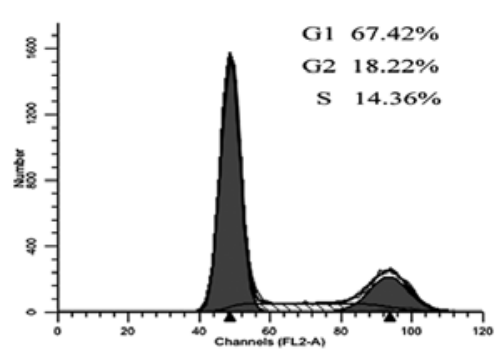

$\mathrm{S} 48 \mathrm{~h}$

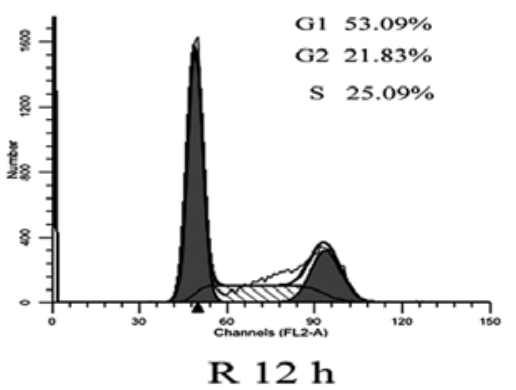

$\mathrm{C}$

\section{$\mathrm{S} 48 \mathrm{~h} \quad \mathrm{R} 4 \mathrm{~h} \quad \mathrm{R} 8 \mathrm{~h} \quad \mathrm{R} 12 \mathrm{~h} \quad \mathrm{R} 24 \mathrm{~h}$}

ARF1

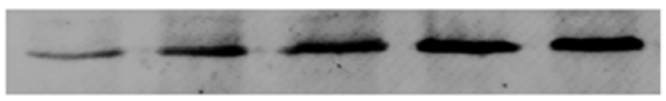

PCNA

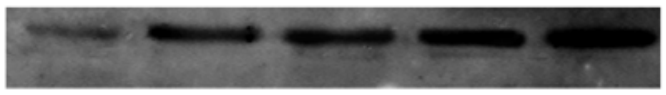

Cyclin D1

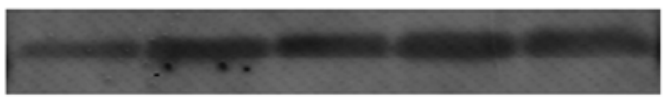

GAPDH

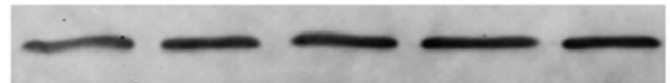

G1 $59.15 \%$

G2 $24.93 \%$

S $15.92 \%$

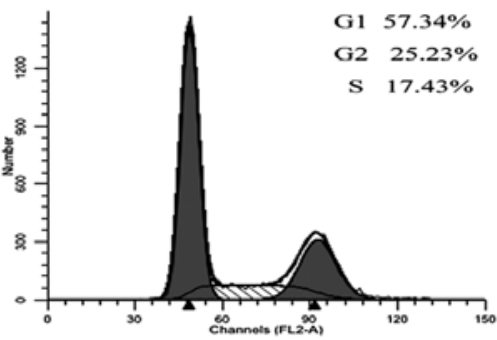

R 4 h

R 8 h

B

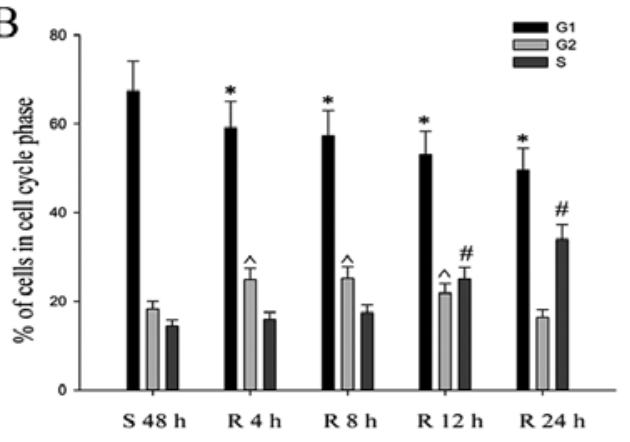

R 24 h

D

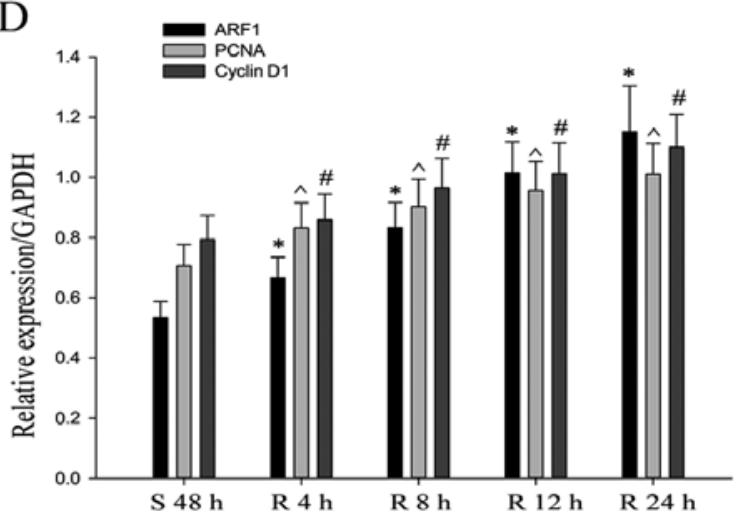

Figure 3. Expression of ARF1 promotes proliferation of EOC cells. (A and B) Flow cytometric quantification of cell cycle progression in HO-8910 cells ${ }^{*}, \#, \wedge<0.05$, compared with G1, G2, and S phase serum starved for $48 \mathrm{~h}$ (S48 h). (C and D) The HO-8910 cells were released by re-feeding with serum, and cell lysates were prepared and analyzed by western blotting using antibodies against ARF1, PCNA and cyclin D1 protein to GAPDH for each time point by densitometry. The data are mean \pm SEM of three independent experiments. $n=3,{ }^{*, \#, \wedge} \mathrm{P}<0.05$, compared with serum starved for $48 \mathrm{~h}$ (S48 h). SEM, standard error of the mean; $\mathrm{S}$, serum starvation; $\mathrm{R}$, serum release.

we used the scatter plot to further determine the relationship between the expression of ARF1 and Ki-67. Pearson's correlation co-efficient revealed that there was a positive correlation between ARF1 expression and Ki-67-based proliferative activity ( $\mathrm{P}=0.005$, Fig. $2 \mathrm{~B})$.

Relationship between ARF1 expression and clinical prognosis of EOC. 119 EOC samples were used for survival analysis. Pearson's $\chi^{2}$ test showed that the histological grade $(\mathrm{P}=0.005)$, FIGO stage $(\mathrm{P}=0.012)$, ARF1 expression $(\mathrm{P}<0.001)$ and Ki-67 $(\mathrm{P}=0.010)$ significantly influenced survival, indicating that these factors were independent prognostic indicators of EOC (Table II). Moreover, as shown in Fig. 4, Kaplan Meier analysis was carried out to calculate the impact of ARF1 expression level on patient survival. The survival curves revealed that, in all 119 clinical cases, patients with high expression of ARF1 might have a poorer overall survival (months) than the others $(\mathrm{P}<0.001$, Fig. 2C). Further, multivariate analysis using Cox's proportional hazards model showed that the histological grade $(\mathrm{P}=0.015)$, FIGO stage
Table III. Contribution of various potential prognostic factors to survival by Cox's regression analysis in the 119 human ovarian cancer specimens.

\begin{tabular}{lccc}
\hline Characteristics & $\begin{array}{c}\text { Hazard } \\
\text { ratio }\end{array}$ & $\begin{array}{c}95 \% \text { confidence } \\
\text { interval }\end{array}$ & P-value \\
\hline Histological grade & 0.512 & $0.299-0.877$ & $0.015^{\mathrm{b}}$ \\
FIGO stage & 0.548 & $0.307-0.981$ & $0.043^{\mathrm{b}}$ \\
Lymph node metastasis & 0.788 & $0.092-6.729$ & 0.828 \\
ARF1 expression & 3.260 & $1.814-5.856$ & $0.001^{\mathrm{b}}$ \\
\hline
\end{tabular}

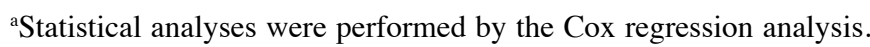
${ }^{\mathrm{b}} \mathrm{P}<0.05$ was considered significant.

$(\mathrm{P}=0.043)$ as well as the expression level of ARF1 $(\mathrm{P}=0.001)$ were 3 independent prognostic factors of overall survival in EOC patients (Table III). 
A

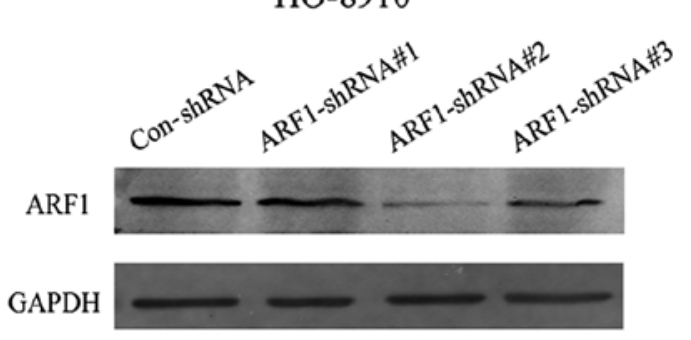

$\mathrm{C}$

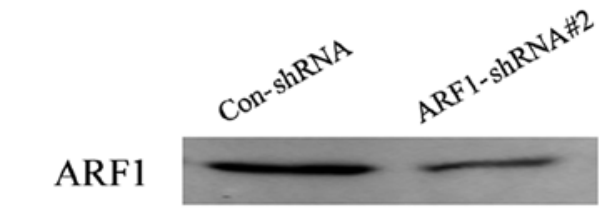

PCNA

Cyclin D1

GAPDH

$\mathrm{E}$

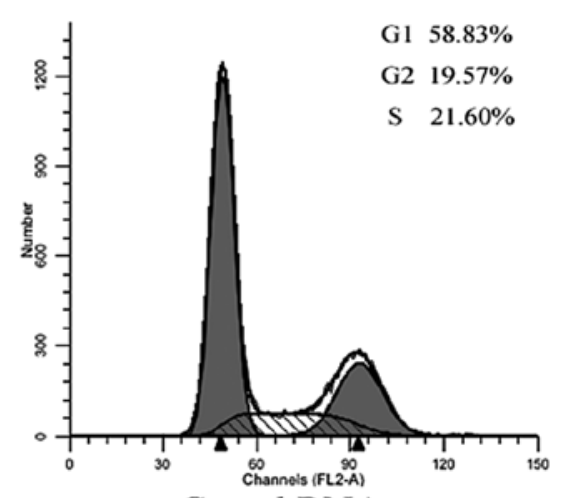

Con-shRNA

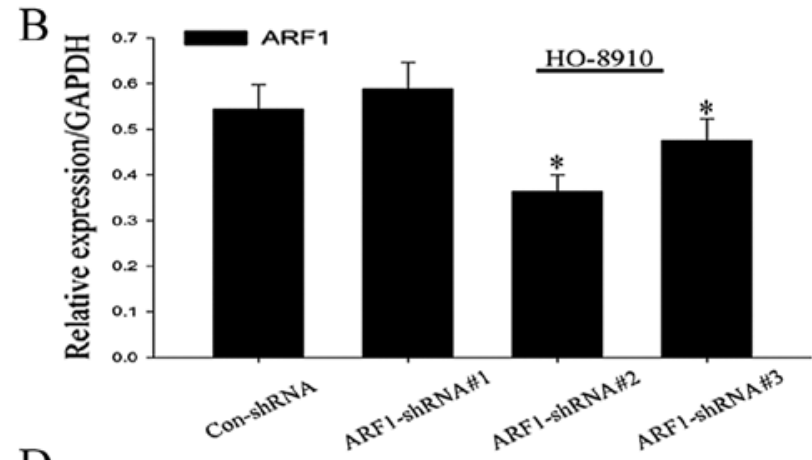

D
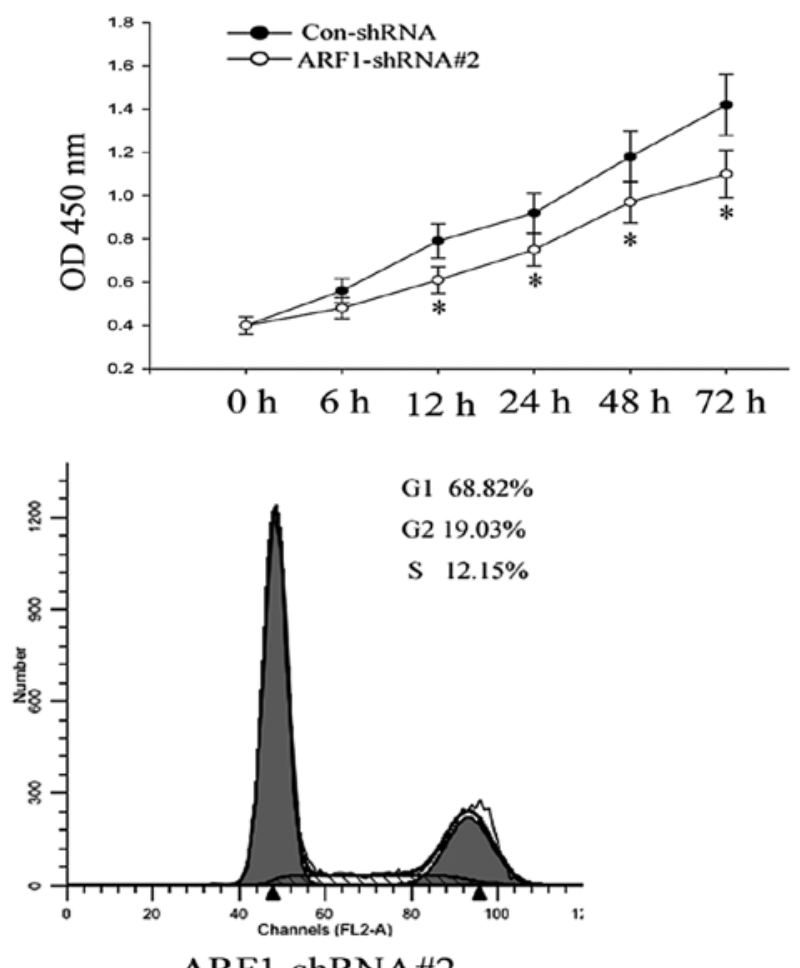

ARF1-shRNA\#2

Figure 4. Knockdown of ARF1 suppressed proliferation of EOC cells. (A) ARF1 protein level was detected by western blotting after shRNA transfection for $48 \mathrm{~h}$ in HO-8910 cells. (B) The bar chart demonstrated the relative level of ARF1 to GAPDH by densitometry. The data are mean \pm SEM. ${ }^{*} \mathrm{P}<0.05$ compared with the control. (C) Western blot analysis of the levels of the cell cycle-related proteins such as PCNA and cyclin D1. (D) CCK-8 assay was carried out to measure cell proliferation. Absorbance was used to examine the control-shRNA and ARF1-shRNA\#2-treated HO-8910 cells. The data are mean \pm SEM ${ }^{*} \mathrm{P}<0.05$ compared with the control of corresponding time points. (E) After knockdown of ARF1 by ARF1-shRNA\#2 in HO8910 cells, flow cytometric analysis of the cell cycle was performed. The data are mean \pm SEM. The results are based on three independent experiments.

ARF1 positively participates in the proliferation progress of EOC cell lines. ARF1 was proven to regulate proliferation of breast cancer cells by regulating the retinoblastoma protein. We found ARF1 was positively correlated with the expression of Ki-67 in EOC specimens. Now, we confirmed that the expression of ARF1 was obviously increased in EOC cells. We chose HO-8910 cell line, which had the highest protein level of the EOC cell lines, to construct a cell serum starvation and releasing model. The result showed that the HO-8910 cells were clearly arrested in the G1 phase and re-entered the $\mathrm{S}$ phase with flow cytometry analysis following serum deprivation for $48 \mathrm{~h}$. The cells in G1 phase were up to $67.42 \%$. After that, the cell population of $\mathrm{S}$ phase gradually increased time dependently, upon continued re-feeding (Fig. 3A and B). Further, we found the expression of ARF1, PCNA and cyclin D1 was significantly increased after serum re-addition as assessed with western blot analysis (Fig. 3C and D). All these results indicated that ARF1 positively participated in the proliferation progress of EOC cells.

Knockdown of ARF1 inhibits proliferation in EOC cell lines. Up to now, we have preliminary cleared the effect of ARF1 in the process of ovarian cancer, in order to further clarify its role in cell proliferation, shRNA was then used to knock down ARF1 expression in the HO8910 cells. HO8910 cells were transiently transfected with control-shRNA, ARF1shRNA\#1, ARF1-shRNA\#2, and ARF1-shRNA\#3. After $48 \mathrm{~h}$, we collected these cell proteins and used western blot analysis to detect the expression levels of ARF1 (Fig. 4A and B). ARF1 protein expression levels were substantially decreased in HO-8910 cells transfected especially with ARF1-shRNA\#2 and to a lesser extent ARF1-shRNA\#3 
A
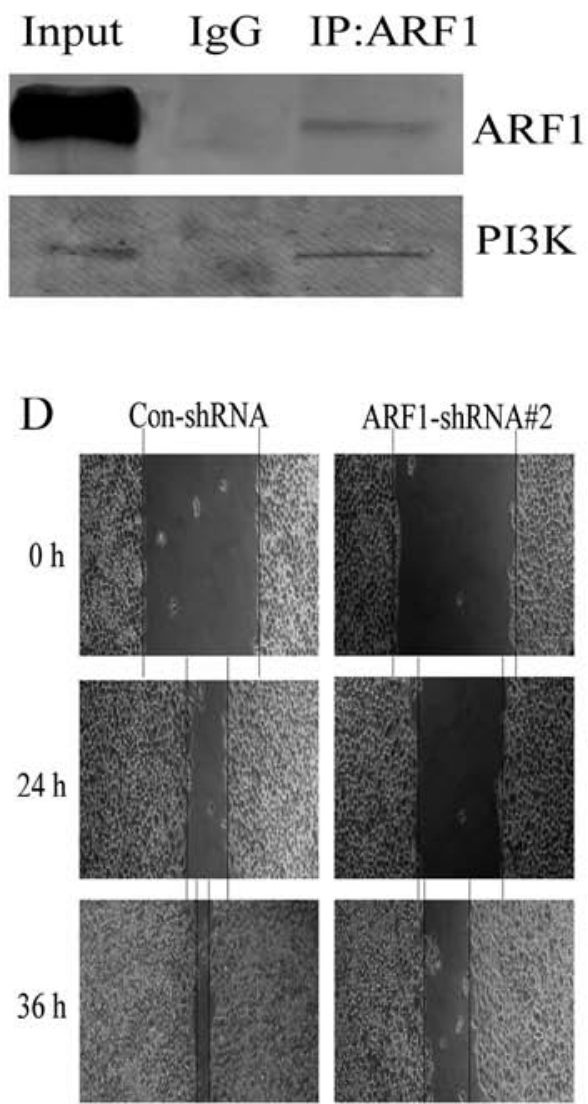

ARF1-shRNA\#2
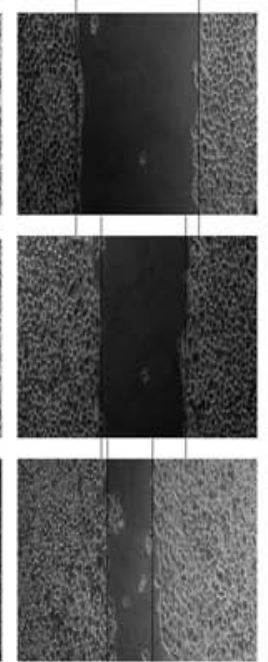

$\mathrm{B}$

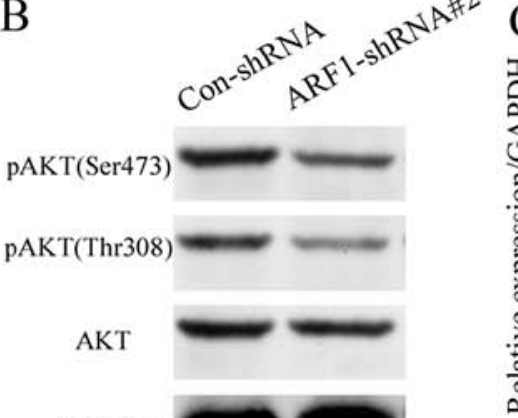

GAPDH

$\mathrm{E}$

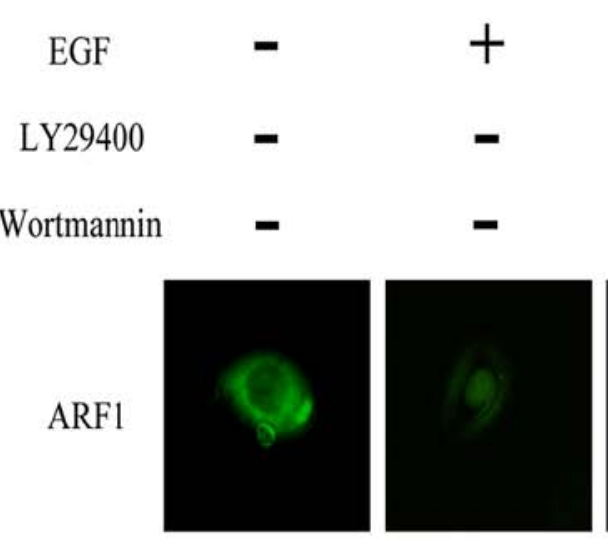

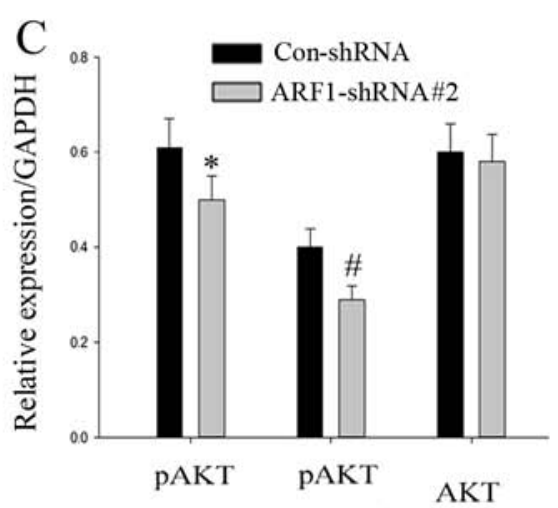

(Ser473) (Thr308)

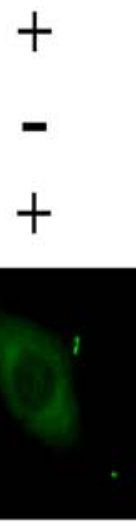

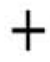
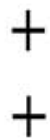

Figure 5. ARF1 promotes cell proliferation and migration through the PI3K signal pathway. (A) Co-immunoprecipitation assay was used for the analysis of interaction between ARF1 and PI3K. (B) The analysis of the expression levels of phosphorylation of AKT (Ser473 and Thr308) and AKT to GAPDH in control-shRNA and ARF1-shRNA\#2 -transfected HO-8910 cells demonstrated by western blot assay. (C) Relative expression level was tested by densitometry. The data are mean \pm SEM. ${ }^{*} \mathrm{P}<0.05$ compared with the control of pAKT (Ser474). ${ }^{\#} \mathrm{P}<0.05$ compared with the control of pAKT (Thr308). (D) Wound healing was carried out to test the effect of ARF1 on cell migration at particular point in time. (E) Cells were stimulated with vehicle, EGF, or pretreated with either wortmannin $(500 \mathrm{nM})$ or LY294002 $(50 \mathrm{mM})$ for $2 \mathrm{~h}$, then visualized by indirect immunofluorescence. All results are representative of at least three repeated experiments.

compared to the control-shRNA-transfected cells. Thus, in the following experiment, we chose ARF1-shRNA\#2 as the experimental model. It was shown that with the significant downregulation of ARF1 expression levels, the expression of PCNA and cyclin D1 were also remarkablely decreased (Fig. 4C).

To further investigate whether the activity of ARF1 affected cell viability, CCK-8 assay was used. As shown in Fig. 4D, HO-8910 cells treated with shRNA suppressed cell proliferation rate compared with the negative control shRNA. In order to explore relevant causes, we analyzed the cell cycle of HO8910 cells transfected with control-shRNA and ARF1-shRNA\#2 by flow cytometry. After transfected for the same period of time, we could see that the proportion of the cells, which were treated with ARF1-shRNA\#2, appeared to be increased in the G0/G1 phase (from $58.83 \%$ to $68.82 \%$ ), while decreased in the $\mathrm{S}$ phase (from $21.60 \%$ to $12.15 \%$ ) compared to the negative control (Fig. 4E). This might suggest that ARF1 is crucial for the G0/G1-S transition and thus the cell growth. Based on the above results, we came to the conclusion that ARF1 could certainly promote proliferation in EOC cell lines, while when knocked down, it was inhibited.
ARF1 significantly affects the ability of migration as well as proliferation of EOC cells by forming a PI3K-dependent feedforward signaling pathway. Previously we have made it clear that ARF1 could obviously promote proliferation of EOC cells. As it was knocked down, this ability significantly weakened. However, the specific mechanisms need clarification and whether there was any signal pathways involved. Considering signaling pathways related to the ability of proliferation in tumor cells, PI3K signaling pathway might be the first one to be considerd. In order to further define the mechanism of ARF1 in detail, we first attempted to verify whether it interacted with PI3K, then, co-immunoprecipitation was used. From the results, we found that ARF1 interacted with PI3K in EOC cells (Fig. 5A). To further support the role of ARF1 in regulating the PI3K/Akt pathway, we investigated if a knockdown of ARF1 would have any effect on the related molecules in PI3K signaling pathways. After transfection, we detected the expression levels of phosphorylation of AKT (Ser473 and Thr308) and AKT by western blot analysis.

As shown in Fig. 5B and C, the expression of pAKT (both Ser473 and Thr308) were notably decreased in HO-8910 cells treated with ARF1-shRNA\#2 compared to the control, while the AKT in these two kinds of cells seemed to be 
consistent. These data support that ARF1 is involved in PI3K pathway activation. The PI3K pathway is involved in a series of biological behavior of tumor cells, such as proliferation, invasion, migration and metastasis. We found, after transfection with ARF1-shRNA\#2 for $24 \mathrm{~h}$, the ability of cell migration also significantly decreased. After the same treatment for $36 \mathrm{~h}$, this situation was more obvious (Fig. 5D). These results suggested that ARF1 played a general role in the proliferation and migration of EOC cell lines through the PI3K pathway. Then, IHC (Fig. 2A) showed that ARF1 located in cell membrane, and the epidermal growth factor receptor (EGFR), also at the plasma membrane is considered a major oncogenic factor, and its presence in tumors is indicative of poor prognosis through activating the PI3K signaling pathway. Given this finding, we hypothesized that the small GTPase ARF1 as a downstream target molecule of PI3K. We used EGF stimulation and pharmacological inhibitors of PI3K for confirmation. A translocation of ARF1 from the cytosol to the membrane compartment was observed upon EGF stimulation. In addition, cells treated with wortmannin or LY294002 showed significantly decreased membrane translocation (Fig. 5E), indicating that PI3K might regulate ARF1 by adjusting its orientation. Taken together, all this illustrated that ARF1 significantly affected the malignant behavior of EOC cells by forming a PI3K-dependent feedforward signaling pathway.

\section{Discussion}

EOC is the most common and lethal histotype of all ovarian cancers with a 5-years survival rate of only $30 \%$. Although traditional therapies such as surgical resection, chemotherapy, and radiotherapy have been widely applied, there has been little improvement in overall survival for several decades, emphasizing the need for new treatments (24). Thus, a thorough understanding of the molecular events associated with the process of EOC is necessary. In the present study, we demonstrate the functional role and clinical significance of ARF1 in EOC.

Previous studies showed that exogenously expressed ARF1 is mainly localized to the ERGIC and the Golgi (25-27), and their depletion induces formation of tubules from the ERGIC (27). Although ARF1 is mostly known for its role in the regulation of the secretory pathway, the demonstration that this ARF isoform is present at the plasma membrane and activated after receptor stimulation provides a new rationale for its role in different receptor-mediated biological functions.

Our current study revealed that ARF1 significantly associated with a poor prognosis in EOC, which was confirmed both by gene expression and protein expression analyses. Moreover, Cox's proportional hazards model also proved that the histological grade as well as the expression level of ARF1 were independent prognostic factors of overall survival in EOC patients. Furthermore, by serum starvation and release experiments, CCK-8 assay and wound healing experiment, it was demonstrated that ARF1 could promote the proliferation and migration rate of EOC cells. With the knockdown of its expression by shRNA in an in vitro experiment, the ability of proliferation and migration and the expression of related molecules such as PCNA, cyclin D1 and others were significantly downregulated. These findings showed that ARF1 played an important role in identifying a poor prognostic result of EOC. Specifically, we showed that this ARF isoform was present at the plasma membrane and regulated activation of the PI3K pathway.

It is well known that class IA PI3Ks are translocated to activate RTKs to regulate cell migration and growth downstream of RTKs (28). Activation of the PI3K/Akt pathway by growth factors is associated with cell survival and growth, as well as proliferation through multiple downstream targets impinging on cell cycle regulation. In this study, we demonstrated that depletion of ARF1 markedly inhibited activation of the PI3K pathway, as assessed by the phosphorylation of Akt. In either case, our data suggested that ARF1 might act as a switch to regulate this key event. Taken together, these findings suggested that ARF1 might contribute to cancer cell progression and migration by controlling the PI3K pathway. While, it is reported that, the PI3K binding site of Gab2 regulated the granule-translocation step and that the SHP2 binding site contributed to plasma-granule membrane fusion. Furthermore, the small GTPase ARF1 was thought to be a downstream target molecule of PI3K (29). Combined with our existing results, we speculate that ARF1 may not only be upstream of the PI3K pathway to regulate its functions, but also can be thought as downstream of this pathway, making it regulated, and this was verified by us. This view also requires further verification in our following studies.

In summary, our studies confirmed that ARF1 was highly expressed in both EOC tissues and EOC cell lines, and its expression was positively correlated with the ability of proliferation and migration of EOC. Furthermore, the knockdown of ARF1 could inhibit both the cell proliferation and migration of EOC. The fact that the depletion of ARF1 had similar effects on EOC cell lines suggests that the mechanisms that we have uncovered may be widely used. Taken together, our findings reveal an unsuspected role for ARF1 and indicates that this small GTPase may be a potential therapeutic target for the treatment of EOC. It is of special interest to note the identification of an inhibitor that specifically prevents ARF1 activation (30). Further studies using such compounds will provide insights into the precise role of ARF1 in tumorigenesis.

\section{References}

1. Lynch HT, Snyder C and Casey MJ: Hereditary ovarian and breast cancer: What have we learned? Ann Oncol 24 (Suppl 8): viii83-viii95, 2013

2. Kucukmetin A, Naik R, Galaal K, Bryant A and Dickinson HO: Palliative surgery versus medical management for bowel obstruction in ovarian cancer. Cochrane Database Syst Rev 7: CD007792, 2010.

3. Keen A, Fitzgerald D, Bryant A and Dickinson HO: Management of drainage for malignant ascites in gynaecological cancer. Cochrane Database Syst Rev 1: CD007794, 2010.

4. Khosravi-Shahi P and Cabezon-Gutierrez L: Antiangiogenic drugs in the treatment of advanced epithelial ovarian cancer. Anticancer Agents Med Chem 12: 982-987, 2012.

5. Bhatt P, Vhora I, Patil S, Amrutiya J, Bhattacharya C, Misra A and Mashru R: Role of antibodies in diagnosis and treatment of ovarian cancer: Basic approach and clinical status. J Control Release 226: 148-167, 2016.

6. Shen DF, Liu X, Yang XF, Fang L, Gao Y, Zhao S, Wu JC, Shi S, $\mathrm{Li} \mathrm{JJ}$, Zhao XX, et al: The roles of parafibromin expression in ovarian epithelial carcinomas: A marker for differentiation and prognosis and a target for gene therapy. Tumour Biol 37: 2909-2924, 2016. 
7. Li W, Zhou Y, Su Y, Ouyang Y, Xie X, Wu Y, Mao C and Chen D IL-23 promotes invasion of esophageal squamous cell carcinoma cells by activating DLL4/Notch1 signaling pathway. Xi Bao Yu Fen Zi Mian Yi Xue Za Zhi 31: 812-815, 820, 2015 (In Chinese). 8. Stuckey A, Fischer A, Miller DH, Hillenmeyer S, Kim KK, Ritz A, Singh RK, Raphael BJ, Brard L and Brodsky AS: Integrated genomics of ovarian xenograft tumor progression and chemotherapy response. BMC Cancer 11: 308, 2011.

9. Sabe H, Hashimoto S, Morishige M, Ogawa E, Hashimoto A, Nam JM, Miura K, Yano H and Onodera Y: The EGFR-GEP100Arf6-AMAP1 signaling pathway specific to breast cancer invasion and metastasis. Traffic 10: 982-993, 2009.

10. Caviston JP, Cohen LA and Donaldson JG: Arf1 and Arf6 promote ventral actin structures formed by acute activation of protein kinase C and Src. Cytoskeleton 71: 380-394, 2014.

11. Stearns T, Willingham MC, Botstein D and Kahn RA ADP-ribosylation factor is functionally and physically associated with the Golgi complex. Proc Natl Acad Sci USA 87: 1238-1242, 1990.

12. Robertson DN, Johnson MS, Moggach LO, Holland PJ, Lutz EM and Mitchell R: Selective interaction of ARF1 with the carboxyterminal tail domain of the 5-HT2A receptor. Mol Pharmacol 64: 1239-1250, 2003.

13. Cohen LA, Honda A, Varnai P, Brown FD, Balla T and Donaldson JG: Active Arf6 recruits ARNO/cytohesin GEFs to the PM by binding their PH domains. Mol Biol Cell 18: 2244-2253, 2007.

14. Hassa PO, Haenni SS, Elser M and Hottiger MO: Nuclear ADP-ribosylation reactions in mammalian cells: Where are we today and where are we going? Microbiol Mol Biol Rev 70 789-829, 2006.

15. Norman JC, Jones D, Barry ST, Holt MR, Cockcroft S and Critchley DR: ARF1 mediates paxillin recruitment to focal adhesions and potentiates Rho-stimulated stress fiber formation in intact and permeabilized Swiss 3T3 fibroblasts. J Cell Biol 143 1981-1995, 1998.

16. Viaud J, Zeghouf M, Barelli H, Zeeh JC, Padilla A, Guibert B, Chardin P, Royer CA, Cherfils J and Chavanieu A: Structure-based discovery of an inhibitor of Arf activation by Sec7 domains through targeting of protein-protein complexes. Proc Natl Acad Sci USA 104: 10370-10375, 2007.

17. Boulay PL,Cotton M,Melançon P and Claing A: ADP-ribosylation factor 1 controls the activation of the phosphatidylinositol 3-kinase pathway to regulate epidermal growth factor-dependent growth and migration of breast cancer cells. J Biol Chem 283 . 36425-36434, 2008.

18. Schlienger S, Ramirez RA and Claing A: ARF1 regulates adhesion of MDA-MB-231 invasive breast cancer cells through formation of focal adhesions. Cell Signal 27: 403-415, 2015.
19. Frame MC: Src in cancer: Deregulation and consequences for cell behaviour. Biochim Biophys Acta 1602: 114-130, 2002.

20. Wheeler DL, Iida M and Dunn EF: The role of Src in solid tumors. Oncologist 14: 667-678, 2009.

21. Ji L, Li H, Gao P, Shang G, Zhang DD, Zhang N and Jiang T: Nrf2 pathway regulates multidrug-resistance-associated protein 1 in small cell lung cancer. PLoS One 8: e63404, 2013.

22. Wang Y, Liu F, Mao F, Hang Q, Huang X, He S, Wang Y, Cheng C, Wang $\mathrm{H}, \mathrm{Xu} \mathrm{G}$, et al: Interaction with cyclin $\mathrm{H} /$ cyclin-dependent kinase 7 (CCNH/CDK7) stabilizes C-terminal binding protein 2 (CtBP2) and promotes cancer cell migration. J Biol Chem 288: 9028-9034, 2013

23. Wang Y, Yang S, Ni Q, He S, Zhao Y, Yuan Q, Li C, Chen H, Zhang L, Zou L, et al: Overexpression of forkhead box $\mathrm{J} 2$ can decrease the migration of breast cancer cells. J Cell Biochem 113: 2729-2737, 2012.

24. Kyriakidis I and Papaioannidou P: Estrogen receptor beta and ovarian cancer: A key to pathogenesis and response to therapy. Arch Gynecol Obstet 293: 1161-1168, 2016.

25. Ara I, Bakir MA and Kudo T: Transfer of Catellatospora koreensis Lee et al. 2000 as Catelliglobosispora koreensis gen. nov., comb. nov. and Catellatospora tsunoense Asano et al. 1989 as Hamadaea tsunoensis gen. nov., comb. nov., and emended description of the genus Catellatospora Asano and Kawamoto 1986 emend. Lee and Hah 2002. Int J Syst Evol Microbiol 58: 1950-1960, 2008

26. Chun J, Shapovalova Z, Dejgaard SY, Presley JF and Melançon P: Characterization of class I and II ADP-ribosylation factors (Arfs) in live cells: GDP-bound class II Arfs associate with the ER-Golgi intermediate compartment independently of GBF1. Mol Biol Cell 19: 3488-3500, 2008.

27. Ben-Tekaya H, Kahn RA and Hauri HP: ADP ribosylation factors 1 and 4 and group VIA phospholipase $\mathrm{A}(2)$ regulate morphology and intraorganellar traffic in the endoplasmic reticulum-Golgi intermediate compartment. Mol Biol Cell 21: 4130-4140, 2010. doi: 10.1091/mbc.E10-01-0022.

28. Burke JE and Williams RL: Dynamic steps in receptor tyrosine kinase mediated activation of class IA phosphoinositide 3-kinases (PI3K) captured by H/D exchange (HDX-MS). Adv Biol Regul 53: 97-110, 2013.

29. Nishida K, Yamasaki S, Hasegawa A, Iwamatsu A, Koseki $\mathrm{H}$ and Hirano T: Gab2, via PI-3K, regulates ARF1 in FceRImediated granule translocation and mast cell degranulation. $\mathrm{J}$ Immunol 187: 932-941, 2011.

30. Orlichenko L, Stolz DB, Noel P, Behari J, Liu S and Singh VP: ADP-ribosylation factor 1 protein regulates trypsinogen activation via organellar trafficking of procathepsin $B$ protein and autophagic maturation in acute pancreatitis. J Biol Chem 287: 24284-24293, 2012. 